\title{
MAPAS DIGITALES Y SOCIEDAD: GEOSEMÁNTICA SOCIAL, EL PODER DEL SENTIDO DE LUGAR
}

\author{
Diego CERDA SEGUEL (Diego.cerda.s@,gmail.com) \\ Centro de Estudios KMLOT, Chile
}

Recibido: $15 / 05 / 2015$

Aceptado: $31 / 08 / 2015$

RESUMEN: Este texto presenta el enfoque denominado geosemántica social, su marco teórico conceptual, su investigación y su aplicación como tecnología social. Realizaremos una exposición en el nivel de resultados del proceso de concepción, estudio y desarrollos de aplicación de esta propuesta disciplinaria que cruza lo geográfico con lo societal. El concepto surge hace una década, a partir de un enfoque de autor sobre el fenómeno emergente de los mapas digitales, en cruce con el poder de las redes sociales y de la funcionalidad sustantiva de anotar sobre ellos; comunicando y socializando lugares. Se expone un tipo de sociología del territorio, que estudia la forma en la que individuos, comunidades y organizaciones, disponen de nuevos recursos tecnológicos, que permiten anotar en mapas (georreferenciación) y con ello generar significaciones e identidades para los lugares y territorios. Nuestro objeto es conocer los recursos sociales de anotación, comunicación, validación de lugares y su despliegue mediante mapas; desde donde se generan fenómenos relevantes para la transformación tecno-societal en curso, considerando desde sus aspectos lúdicos y expresivos, así como contingentes y estratégicos, alcanzando el concepto de geopolítica (y también micro-geopolítica). Se examina el nivel de familiaridad entre la noción de «neogeografía» y la geosemántica social, realizando un breve análisis de tres plataformas de mapas sociales: Waze, Foursquare y OpenStreetMap. Finalmente se hará repaso evolutivo de tres textos del autor; publicados entre los años 2005 y 2013 , que permitirá entregar una definición actualizada del concepto.

PALABRAS CLAVE: Geosemántica social, neogeografía, mapas digitales, redes sociales, web semántica, georreferenciación.

\section{DIGITAL MAPS AND SOCIETY: SOCIAL GEOSEMANTIC, THE SENSE OF PLACE POWER}

ABSTRACT: This paper presents the standpoint known as Social Geosemantic, its conceptual framework, its research, its development and its application as social technology. We will expose at the level of the results of the design process, and the study and development of this disciplinary proposal that crosses the (neo) Geographical with Societal facts. The concept emerged a decade ago, from an author's view about the emerging phenomenon of digital maps, along with the power of social networks, plus the substantial functionality that is to annotate on maps; communicating and socializing places. This is a type of sociology of the territory, which studies the way how individuals, communities and organizations have new technological resources that allow them annotating on maps (georeferencing) and thus generate meanings and identities for places and territories. Our purpose is to study the social resources for annotation, communication and validation of places and its deployment using digital maps; from where 
relevant phenomena are generated that impacts on techno-societal transformation, considering from its playful and expressive aspects as well as contingent and strategic aspects, reaching the concept of geopolitics (and micro-geopolitics). The level of familiarity between the notion of «neogeography» and social geosemantic is put under review, with a brief analysis of three social maps platforms: Waze, Foursquare and OpenStreetMap. Finally we will review - from an evolutionary sidelight - three related texts from this author; published between 2005 and 2013, which will help us to deliver an updated definition of the concept.

KEY WORDS: Social Geosemantic, Neogeography, Digital Maps, Social Networks, Semantic Web, Georeference.

\section{INTRODUCCIÓN}

La geosemántica social que plantearemos coloca a la sociología como potencia de observación y acción cartográfica, frente al universo de los mapas geográficos sociales en internet, tales como Waze, Foursquare, OpenStreetMap o los servicios cartográficos y de mapas de Google Inc., entre otros. Planteamos que los mapas que admiten las interacciones sociales tienen un enorme potencial para dar sentido a lugares y territorios, tanto en términos virtuales como reales, en un proceso emergente relativamente muy reciente en internet ${ }^{1}$, Este enfoque conceptual y práctico, tiene el propósito de impulsar una mejor comprensión de la relación entre individuos, comunidades y organizaciones respecto de los espacios geográficos que les conciernen, mediante el uso de los medios sociales ${ }^{2}$.

\footnotetext{
${ }^{1}$ Entendemos como internet la red viva de nuestra sociedad, «internet es el tejido de nuestras vidas» en la expresión del sociólogo Manuel Castells en su Galaxia Internet (2001). Consideramos como hito inicial de la masificación de la disponibilidad para anotar mapas, el lanzamiento de Google Maps en 2005, año en que también se lanzó Google Earth.

${ }^{2}$ Existe el ámbito específico de investigación denominado locative based social media, medios sociales basados en la localización, nuestro enfoque es totalmente familiar con el ámbito de estudio, sin embargo corresponde a una tradición investigativa distinta. Ver artículo «Social Media» en Wikipedia http://en.wikipedia.org/wiki/social_media

NOTA sobre el uso de Wikipedia en este artículo: Se hará uso intensivo de la Wikipedia; se considera de gran valor tener acceso al punto de vista social que los editores de Wikipedia constantemente están actualizando en las definiciones. Como referencia de citación responde a ese hecho, la enciclopedia abierta permite que los artículos consultados sean de reciente actualización e incorporen el trabajo colaborativo ciudadano, desde distintos puntos de vista sobre las materias, se trata de seguir lo que la gente dice, Wikipedia sirve para esto. Se considera en algunos casos artículos en inglés, en tanto la lingua franca de nuestra época, especialmente en términos del desarrollo de la ciencia, los neologismos y las aplicaciones, constantemente actualizada para acceder a definiciones en constante evolución. Somos conscientes, en todo caso de las debilidades de Wikipedia, las acciones vandálicas, los conflictos semánticos políticos, la obsolescencia e inconsistencia conceptual, etc. El caso de las citas a Wikipedia usadas en un artículo científico se justifica por el valor de las dinámicas de web 2.0.
} 
Para nuestra concepción es esencial comprender el recurso de la georreferenciación ${ }^{3}$ de lugares de manera social, es decir: teniendo en mente que se trata de un fenómeno tecno-societal emergente, el cual se potencia y escala con la disponibilidad masiva de tecnologías de interacción digital en red social, mediante la variedad de dispositivos móviles y ordenadores personales, y hacia adelante también con la llegada de dispositivos aeronáuticos y robóticos (drones) de uso doméstico y recreativo.

Este texto considera a las plataformas de mapas digitales sociales en la concepción de un fenómeno emergente, que debe ser observado y estudiado para abrir nuevas formas de entender, vivir y mejorar armónicamente nuestra interacción con los espacios geográficos. Las plataformas en cuestión deben cumplir el requisito de permitir la anotación de mapas digitales, en cualquiera de sus expresiones, y también facilitar los actos de compartir, difundir y responder las anotaciones con otras anotaciones, o con votaciones en las plataformas de medios y redes sociales; en lo que reconocemos como prácticas de la web 2.0.

Sin la capacidad de anotar por parte de los usuarios, las plataformas de mapas se tornan irrelevantes para nuestro enfoque. La complejidad técnica de la georreferenciación resulta también irrelevante, toda vez que es una tecnología ya disponible, importante desde su uso social; y específicamente, porque lo que cuenta para nosotros es la anotación en su contenido e implicaciones sociales, como mensaje con sentido en alguna plataforma digital.

El acto de georreferenciar en plataformas sociales, en sus distintas variantes lógicas ${ }^{4}$, son significativas para nosotros en la medida en que esas anotaciones tienden a (y permiten) aportar en la construcción de sentidos, significados e identidades para los lugares y territorios, en actos tales como subir fotos a un mapa y compartirlas; indicar que te gusta un lugar en Foursquare; generar

\footnotetext{
${ }^{3}$ El término Georreferenciación nos interesa en tanto se expresa como fenómeno social, en plataformas sociales en la red, que permiten anotar sobre un lugar en mapas web. Para este estudio se entiende en general «anotar» mapas como sinónimo de «georreferenciar», considerando las distintas facetas del fenómeno, en los actos de anotar, publicar, compartir, discutir, intervenir, enriquecer, buscar, o acceder datos sobre un mapa web social. Se comprende que la definición técnica de la georreferenciación tiene otra especificidad en torno de los Sistemas de Información Geográficos. Para nuestro objeto la georreferenciación es relevante en tanto georreferenciación social, que entendemos como la anotación con significado social en mapas web. Ver Georreferenciación. http://en.wikipedia.org/wiki/Georeference

${ }^{4}$ Las variantes lógicas son las alternativas de recursos de software (funcionalidades, permisos) que se pueden aplicar a la anotación, se entiende como el enriquecimiento e incrustación de datos multimedia en el mapa.
} 
información de tráfico vehicular como en Waze; enviar una dirección para llegar a un evento con Google Maps, o componer y compartir ficheros *.kml en Google Earth, son todos actos propios de un orden en el cual los lugares pueden ser hablados por los usuarios.

Estas formas de georreferenciar ocurriendo todo el tiempo en la red, almacenadas en plataformas sociales para su consulta y acceso, permiten a los lugares hacerse protagonistas en fenómenos de expresividad y de generación de significados que pueden activar dinámicas territoriales que son de pleno interés desde la sociología, la política, la geografía y la tecnología.

Los mapas sociales web adquieren con ello el potencial de ser canales de comunicación social horizontal a través de las redes sociales en torno de tópicos que involucran y activan lugares. Sean estas anotaciones relativas al valor contemplativo de un paisaje, como una foto posicionada en el mapa, con un comentario poético a la escena paisajística; o sobre la calidad de un hotel posicionado en un mapa web de turismo; o una anotación sobre la calidad humana de la gente de un lugar, o también, una anotación sobre una amenaza a determinado ecosistema. En todos estos casos los lugares son hablados por estos usuarios diferenciales en su experticia o in-experticia cartográfica.

La observación de estos fenómenos desde la geosemántica social, hace inteligibles los territorios en el tiempo, fundando narrativas referenciales desde sus cargas de significación e identidad en el universo de intersubjetividad del mundo de la vida cotidiana, observando cómo emerge el sentido de los lugares anotados en sistemas de mapas sociales a través de las redes sociales, con el concurso de individuos, comunidades, organizaciones e instituciones, que actúan como agentes transformadores de las propiedades singulares de un lugar.

Se considera que el fenómeno emergente que planteamos observar, estudiar e intervenir, implica un medio valioso y positivo para ayudar a construir sinergias entre los espacios geográficos y los grupos humanos, siendo una manera original de generar territorialidades que produzcan mejoras significativas en la sociedad, a partir de unidades socio - espaciales diferenciadas, especialmente a partir de la visión local del espacio geográfico. La anotación que incorpora una filiación territorial está en condiciones de materializar, a través de la Web, sentimientos de pertenencia territoriales, facilitando actos de «autodescripciones del territorio», y capturar los mensajes asociados a favor y en contra a esta «autodescripción» ${ }^{5}$.

\footnotetext{
${ }^{5}$ En su desarrollo del concepto de «El territorio como sistema autopoietico», PFEILSTETTER (2011) cita a MAIER y SEDLACEK (2009) para describir el territorio desde la perspectiva local;
} 
La geosemántica ${ }^{6}$ emerge como examen y expectativa del manto de sentido a la vista con los medios comunicativos e interactivos de georreferenciación social. Sin embargo, la georreferenciación no implica geosemántica, puesto que no toda georreferenciación es social; de hecho la mayor parte de los actos de georreferenciar ocurren hoy en el nivel técnico especializado de los sistemas de información geográficos.

Una vez que un lugar es hablado (anotado, georreferenciado) por usuarios y se abre al interés de otros individuos, comunidades, organizaciones y/o instituciones, puede adquirir un protagonismo nuevo en tanto lugar, pero también puede adquirir nuevas identidades, de acuerdo a quiénes hablen sobre dicho lugar; y en este acto, estas anotaciones sean entendidas como «voces del lugar», es decir: anotaciones que hacen hablar a un lugar. Las anotaciones sociales son el alimento de construcciones de sentido sobre los mapas digitales, que pueden adquirir aspectos, dimensiones y validez territoriales relevantes. GRAHAM (2009) plantea que «los lugares son siempre palimpsestos». Efectivamente, en la geosemántica social los lugares son palimpsestos ${ }^{7}$; capas de sentido sobre capas de sentido que se producen en las plataformas digitales de mapas pero que en gran parte son alimentados por un sentido de lugar, una memoria de lugar, un espíritu de lugar común. Estas capas semánticas, una sobre varias, van construyendo un saber semántico narrativo del espacio geográfico donde se acentúa precisamente la semántica que cubre un lugar de sentido; a partir de sucesos, significaciones e identidades. Internet hace que esos movimientos narrativos puedan ser simultáneos.

La lectura sociológica del fenómeno descrito busca extraer y perfilar sentido social territorial e identitario de los lugares anotados, así como sus dinámicas generativas en la red, desarrollando una tipología que procure enriquecer los potenciales semánticos - narrativos de esta actividad, en favor de una mejor, más sostenible y armoniosa relación entre lugares, personas, organizaciones y potencias territoriales.

El autor plantea un marco teórico levantado desde la práctica investigativa de la geosemántica social; la cual comprende la observación y estudio de las

allí explicita la hipótesis de los autores que cita: «La hipótesis está en que el sentimiento de pertenencia de «mi tierra», produce efectos económicos y sociales positivos». En PFEILSTETTER, R. (2011).

${ }^{6}$ Existe un proyecto específico de Geociencias denominado Geosemántica. Dentro de la bibliografía a citar más adelante se tratará este aspecto conceptual - terminológico.

${ }^{7}$ «Users of these services can then virtually touch down to any point on the globe and immerse themselves in local knowledge about that place. A virtual palimpsest of place is truly created. Photographs, descriptions, blogs, narratives, advice, reviews and stories are all tied to a specific place, and can be instantly accessed» GRAHAM, M. (2009). 
formas de apropiación social de los espacios geográficos, mediante las anotaciones, discusiones, votaciones y el compartir usando plataformas de mapas electrónicos.

Con el acto de anotar un mapa surge el potencial de semantización de un lugar y su comunicación horizontal en el mundo. Semantizar quiere aquí decir dar sentido social, considerando desde un nivel superficial de información social sobre un lugar, hasta un nivel ontológico social que se aplica a la relación de individuos, comunidades, instituciones e idearios, con los espacios geográficos significativos. Dicho potencial es visible y empieza su operación cuando incorpora acentos en los que emerge la anotación intensiva, emocional e inmediata de los lugares, lo que desencadena la producción de un nuevo tipo de «sentido de lugar», sustancializando la anotación como cuestión en discusión activa, con sucesivos actos de anotar, publicar, «compartir» e interactuar con datos cartográficos híbridos ${ }^{8}$ en mapas electrónicos.

El nivel de hibridez de los datos de hecho se expande si consideramos factores de libertad para anotar lugares (creatividad, ocio, intenciones individuales, etc.), donde no hay restricciones normativas ni veritativas: la anotación no necesita ser correcta ni verdadera para poder ser publicada, compartida y discutida.

Lo que observamos sale del dominio de la cartografía positiva y entra en el ámbito de la expresividad social y sus consecuencias, adquiriendo un abanico de entradas de interés sociológico, desde lo trivial a lo sustantivo; situaciones polémicas; como también creatividad, ficción y artificio para describir o asignar atributos, propiedades, etc. a lugares en un mapa digital. Las anotaciones más indeterminadas o intempestivas tienen de hecho posibilidades de tener consecuencias de realidad en los lugares físicos 9 .

El enfoque sociológico inicial de análisis para este ámbito de estudio ha sido la sociología política weberiana (WEBER, 1992), disciplina comprensiva que se encarga del estudio de los sistemas de dominación en la sociedad, la forma en que emerge el poder y la autoridad de la acción social, considerando sus

\footnotetext{
${ }^{8}$ Nos referimos a las anotaciones sociales contagiosas que se expanden viralmente, incrementando su volumen de metadatos y actividad social, incorporando otras anotaciones con datos enriquecidos y multimedia, esto mientras se desarrolla su ciclo de relevancia para la geosemántica social.

${ }^{9}$ Del mismo modo que la Teoría del Caos señala, que el aleteo de una mariposa en Shanghái puede provocar una tormenta en Nueva York, una anotación intempestiva sobre un mapa social puede generar consecuencias inesperadas en el lugar físico, mediante los comportamientos caóticos que adquiere la comunicación en redes sociales en el fenómeno denominado «viralidad», puesto que emula el comportamiento de crecimiento y contagio agresivo de un virus.
} 
interacciones legítimas y no legítimas respecto de la «política real»: aquella política institucionalizada que rige a los estados y por tanto define los territorios de su jurisdicción.

Hasta hoy el territorio, a pesar de su polisemia y uso general desde la zoología hasta la psicología social, ha sido un concepto propio y jerárquico de la geografía política, bajo una óptica administrativa y jurisdicciona ${ }^{10}$. El Estado moderno está compuesto de un territorio oficial declarado, con sus divisiones geográficas con toponimias, delimitación, uso, destinación, jerarquía, etc. Las políticas públicas territoriales son expresión de la construcción jerárquica de los territorios del Estado. Frente a esta hegemonía conceptual, la forma de dar sentido a los lugares mediante la anotación social significa intervenir sobre espacios geográficos virtuales que son representación del espacio físico; y de este modo potencialmente intervenir este orden oficial definido.

Es precisamente por la importancia de esta definición estatal del territorio, hegemónica y con soberanía jurisdiccional, que nos interesa el proceso por el cual una comunidad que blande un mapa como bandera reivindicativa, puede convertirlo en medio de comunicación viral efectivo mediante los canales de redes sociales y recursos de web 2.0, pudiendo obtener acceso a una difusión, discusión y puesta en agenda pública. La definición cartográfica puede ser adjudicada exitosamente y hegemonizar la forma en que debe ser comprendido un espacio geográfico puesto en cuestión, con ello se realiza la transferencia del significado geográfico político hacia nuestra óptica geosemántica.

De acuerdo a nuestra práctica de observación de este fenómeno, esta sociología política se encuentra conceptualmente adaptada al carácter generativo y emergente de las anotaciones en mapas digitales y su activación en redes sociales; enfocándose en sus expresiones, tales como la alimentación social de bases de datos, los usos sociales emergentes de estos recursos y sus potenciales. De este modo hemos apuntado hacia los eventos conflictivos de anotaciones en mapas, respecto de tipos de casos, por ejemplo: el grado de autoridad de una anotación contenciosa realizada por un usuario anónimo; especialmente cuando esa anotación (y la definición social que propone) no es aceptada por determinado grupo de personas que pueden también, en respuesta, anotar una propuesta de definición antagónica del lugar en el mapa digital, iniciando un litigio geosemántico. Son representaciones de antagonismos territoriales reales, que de hecho reflejan relaciones conflictivas sobre cuál es la definición (y propiedad) correcta de un lugar. Desde esta sociología política,

${ }^{10}$ Ver artículo Territorio en Wikipedia. http://es.wikipedia.org/wiki/territorio 
la posibilidad de anotar en el mapa significa un acto de intervención potencialmente estratégico que puede acompañar situaciones contingentes de conflicto social, político, cultural, religioso o, en general, de tipo emergente.

Aquel que anota en un mapa, puede anotar no sólo afirmaciones contenciosas, sino que también puede plantear una descripción totalmente distinta, como en el caso de una ficción territorial ${ }^{11}$; esa ficción puede no constituir verdad en ese momento, pero posee condiciones para generar «situaciones de verdad», en la medida que adquiere vida virtual en fenómenos de contagio viral probabilísticos; los cuales pueden alcanzar masas impresionantes de interacciones (votaciones, comentarios, actividad en foros, etc.).

Al incluir y considerar las ficciones de lugar o las ficciones territoriales, nos alejamos aún más de los criterios científicos de la cartografía, y aceptamos todas las anotaciones sobre mapas digitales como recursos de expresión de sentidos de lugar válidos en principio (desde luego, sin considerar aquellas anotaciones que corresponden a errores lógicos), los cuales se extienden mediante las redes sociales, como manifestaciones de un orden emergente de producción de significado territorial a través de la web.

Las anotaciones en mapas digitales constituyen instancias que pueden adquirir vida propia, mediante diversos medios de validación en términos sociales: por ejemplo, al encender el apoyo, la colaboración, los comentarios o la resistencia de otros usuarios, comunidades e instituciones, pueden alcanzar de esta manera el estatus de afirmaciones hegemónicas sobre un lugar en cuestión. Esto considerando la variedad de tipos de anotaciones, en lo que va desde anotar puntos precisos en la esquina de una plaza, hasta anotar mayores extensiones de espacio geográfico; de este modo los lugares son puestos a hablar; o más bien, a ser hablados por los internautas en las plataformas de mapas digitales, de medios y redes sociales. Estas anotaciones han sido generadas desde los más diversos puntos de vista, desde juicios interesados en promover una definición del lugar hasta juicios lúdicos, creativos y posiblemente desinteresados sobre el lugar.

Desde el punto de vista sociológico político, la validez apunta a la corporización de una legitimidad que otorga autoridad sobre un territorio o lugar. Dado que nos encontramos en un espacio conceptual irruptivo, tal vez sea más preciso hablar de micro-legitimidad para referirnos a los pequeños

\footnotetext{
${ }^{11}$ Nos referimos a afirmaciones sobre lugares reales (que están en el mapa): fábulas o referencias mitológicas y/o literarias, entre muchas otras ficciones territoriales. Más adelante se volverá a este concepto.
} 
espacios geográficos, sobre los cuales se puede instalar una definición hegemónica válida de un lugar, en un proceso que podría simular la construcción a escala de espacios micro-geopolíticos, tal como se verá más adelante.

El marco teórico resultante de este proceso de observación, estudio y reflexión sobre el fenómeno social de los mapas digitales y sus dinámicas actuales y potenciales de la anotación en redes sociales de los puntos de vista de diversos sujetos cartográficos y sus efectos intersubjetivos, ha sido sintetizado por medio de la siguiente ecuación axial ${ }^{12}$ :

\section{TIERRA + SENTIDO $=$ TERRITORIO}

Entendiendo por TIERRA los infinitos lugares en el mundo y SENTIDO como el significado anotado y los elementos identitarios contenidos. En su adición «+» generan el material para entregar identidad y territorialidad a los espacios geográficos y de este modo generar TERRITORIO desde la fuente directa de las personas, los internautas y sus dinámicas interactivas. Para que esta ecuación se eche a andar, se necesita que el TERRITORIO resultante sea a su vez legitimado en el desenlace de estas dinámicas, que involucran otros usuarios, comunidades o instituciones en la expresión digital de redes sociales ${ }^{13}$.

La ecuación geosemántica describe de manera antelatoria la generación de SENTIDO DE LUGAR en la sociedad contemporánea, en la cual el territorio emerge en tanto rendimiento comunicativo y participativo de la interacción humana mediante los mapas digitales, así como su discusión y difusión mediante las redes sociales.

Para desarrollar estas ideas en un marco teórico con un nivel de madurez suficiente, y ser planteadas aquí, el autor ha recorrido algo más de una década de trabajos, en la que ha sostenido la publicación de diversos artículos, columnas, ponencias y ensayos. Con ello se ha avanzado en la composición de un cuerpo conceptual fundado en la observación sociológica del fenómeno global y local de los mapas electrónicos, y de sus prácticas sociales, generadas a través de las diversas tecnologías de red para la interacción «en el mapa», puestas a disposición de internautas comunes y corrientes hace ya diez años, puesto

\footnotetext{
${ }^{12}$ Ecuación formulada en 2008, discutiremos adelante esta publicación específica.

${ }^{13}$ Las redes sociales nos interesan desde un punto de vista semántico, es decir: en tanto son capaces de articular narrativas y vehiculizar contenidos a través de los autores, actores, agentes y sujetos geosemánticos, que dan significados y sentido a nuestro objeto de estudio, que es territorial.
} 
que consideramos la aparición de Google Maps en febrero del año 2005 como hito inaugural del fenómeno geosemántico social.

Uno de los principales medios para observar las anotaciones en mapas digitales es examinar la orientación funcional de algunas de las arquitecturas virtuales existentes; desde el punto de vista de sus funcionalidades de anotación, junto al estimado de usuarios inscritos. Más adelante pondremos en práctica este enfoque, realizando un breve análisis de cada una de las tres plataformas de mapas interactivos sociales que ya hemos mencionado: Waze, Foursquare, OpenStreetMap; además tendremos una consideración analítica aparte con Google Inc. y sus servicios de cartografía, mapas e imágenes satelitales.

\begin{abstract}
Al examinar estas plataformas descubriremos que los medios para desarrollar los potenciales de anotación geosemántica social ya están disponibles en la internet de hoy, y de este modo lo están sus expresiones de uso más virtuosas; medidas por su impacto en la producción de significación e identidad territorial real, sobre los espacios geográficos que son significativos para los individuos, las comunidades, las organizaciones y las instituciones.
\end{abstract}

Asumimos para esto la validez de una visión integral de la vida social a través de la red de redes. Resaltamos por ello el carácter fenomenológico ${ }^{14} \mathrm{de}$ la «entrada» a este marco teórico de sociología del territorio.

Del mismo modo que la mayoría de las plataformas de mapas son abiertos en internet, comprendemos que son parte de un fenómeno que ocurre en el orden noosférico ${ }^{15}$, en el cual el planeta Tierra mismo adquiere protagonismo en su curvatura, en sus diferencias estacionales, del huso horario, así como

\footnotetext{
${ }^{14}$ Nos remitimos a la fenomenología social de Alfred Schutz (1989), concentrándonos en el fenómeno de las anotaciones en mapas digitales y la manera en que son capaces de cobrar vida en las redes sociales y dar sentido a los lugares. Nuestro enfoque toma el principio investigativo de su sociología de la vida cotidiana para enfocarlo sobre la anotación como fenómeno vivo que define un espacio con un sentido significativo para «el mundo de la vida».

${ }^{15}$ El concepto de Noosfera fue desarrollado por Pierre Teilhard de Chardin a mediados del siglo XX, que a su vez lo toma de Vladimir Vernadsky, como resultado de la evolución de la conciencia universal. Proviene de la compleja palabra griega NOUS, corrientemente asociada a la tradición aristotélica, traducido de la manera más general como MENTE: Noosfera es para nosotros por tanto, una esfera mental de pensamiento en la malla de telecomunicaciones sociales significativas que cubren el globo terrestre. La Noosfera se entiende como el universo de pensamientos que rodean el planeta y que generan un espíritu del tiempo: zeitgeist. Sobre este último concepto Google ha creado un índice de acuerdo a lo que se le está consultado, Ver: Zeitgeist de Google. Sin embargo el nivel de observación geosemántico exige un concepto de Zeitgeist que incorpora las voces de los lugares. Ver: Noosfera, artículo de Wikipedia:

http://es.wikipedia.org/wiki/Noosfera
} 
una serie de variables geográficas que a veces inciden en el carácter de las sociedades y su devenir geoespacial. Especialmente para el propósito de este estudio, consideramos valioso el concepto de noosfera en sus variables culturales, civilizatorias y estratégicas, tanto a nivel micro como macro, que están vivas en internet y que son representación virtual de espacios físicos reales. La noosfera implica para nuestro enfoque una vía para comprender y facilitar a los lugares ser hablados, para ser expresados y para hacerse parte, con sus fragmentos complementarios de significación, de la gran discusión que de manera integral y viva nos une como planeta.

Por todo esto, nuestra propuesta de geosemántica social nace reflejándose en el programa de la web semántica ${ }^{16}$. Nuestra geosemántica es planteada en un inicio (2005), como un proyecto que toma el modelo de la web semántica para plantear un proyecto hipotético de una «web geosemántica social» en el que todos los datos sociales del planeta pudieran estar organizados en una especie de «hiper-enciclopedia» dedicada a posicionar (georreferenciar) toda la información social: pasada, presente y en producción (tiempo real), relacionada con lugares, ocupando la lógica de estructuración y alimentación de base de datos de la web semántica sobre una interfase de usuario similar a Google Earth (geo-navegador), y una arquitectura de colaboración inspirada en Wikipedia, como veremos adelante.

Para argumentar lo hasta aquí expuesto, primero se considerará un análisis de la concepción de la «Neogeografía» en su relación con este enfoque. Para respaldar la argumentación sobre el carácter emergente de nuestro enfoque se hará presentación de un examen a las plataformas digitales de mapas sociales existentes y que han sido exitosas: Waze, Foursquare, OpenStreetMap y Google Inc. Posteriormente realizaremos una recapitulación y relectura de las principales tres publicaciones de los años, 2005, 2008 y 2013 dedicadas al desarrollo de la geosemántica social. Cada uno de estos textos constituye un escalón de elevación de la reflexión geosemántica, hasta llegar al nivel de formular una serie de arquitecturas web que proponen nuevos enfoques para el desarrollo de tecnologías de información territorial.

\footnotetext{
${ }^{16} \mathrm{El}$ proyecto de web semántica originariamente formulado por el World Wide Web Consortium, pero que ha devenido en varios proyectos abiertos y privados con casi dos décadas de desarrollo y significativas inversiones de recursos. Los resultados de estos proyectos son aún poco visibles socialmente, sin embargo, es probable que sus mayores utilidades sean visibles en la trastienda de internet, del mismo modo que la actividad de minería de datos es privada y por tanto socialmente invisible en la vida cotidiana, aunque sin embargo «se mueve».
} 


\section{NEOGEOGRAFÍA Y GEOSEMÁNTICA SOCIAL}

«Neogeography (literally «new geography») is the use of geographical techniques and tools for personal and community activities or by a non-expert group of users [1] Application domains of neogeography are typically not formal or analytical»

Neogeography en Wikipedia ${ }^{17}$

El trabajo sobre la geosemántica social ha sido rotulado a veces dentro del término neogeografía, tanto por lectores como por su propio autor. Si bien en un principio se ha integrado este concepto, después de sucesivos análisis, y dado que la neogeografía es aún una noción muy amplia y por ello compleja, se ha llegado a una definición focalizada del concepto de «neogeografía». Para desarrollar dicha definición platearé primero las similitudes diferencias y distancias entre el término genérico de neogeografía y la disciplina que aquí se plantea: la «geosemántica social». Como expresión paradigmática de la neogeografía se hará examen breve al final de este capítulo de tres plataformas de mapas sociales: Waze, Foursquare, y OpenStreetMap.

A veces el concepto, la palabra y su musicalidad en el lenguaje pueden ser difíciles de asimilar; por ello planteo también que podemos considerar como sustituto del término geosemántica social, el término más genérico de «sociología del territorio»; desde luego hablamos de «un tipo» de sociología del territorio y no de otras que puedan existir en el amplio espectro de la investigación sociológica. Se trata de aquella sociología que se instala en la antesala de la geografía, para entregar un aporte comprensivo y novedoso sobre lo que en adelante podemos designar como «territorios»; ello después de haber examinado las herramientas de mapas sociales, las narrativas territoriales observables y analizado los actos de «compartir» esos mapas y lugares dentro de lo que se ha denominado web 2.0.

Los mapas han sido pensados comúnmente como medios para ayudar a llegar desde un punto A hasta un punto B. Ese ha sido su uso social preferente; la puesta de los mapas en plataformas 2.0 implica ampliar sus funcionalidades

\footnotetext{
${ }^{17}$ Hacemos cita de este fragmento de definición desde la versión en inglés por considerar que la mayor cantidad de literatura sobre Neogeografía se ha producido en ese idioma, la cual se remonta al año 1922. "The term neogeography was first defined in its contemporary sense by Randall Szott in 2006. He argued for a broad scope, to include artists, psychogeography, and more. The technically oriented aspects of the field, far more tightly defined than in Scott's definition, were outlined by Andrew Turner in his Introduction to Neogeography (O'REILLY, 2006). The contemporary use of the term, and the field in general, owes much of its inspiration to the locative media movement that sought to expand the use of location-based technologies to encompass personal expression and society» Ver artículo Neogeography, en Wikipedia:

http://en.wikipedia.org/wiki/Neogeography
} 
al ámbito de la comunicación y la interacción en lógicas de red social. Por ejemplo, observemos las guías turísticas; estas plantean una narración descriptiva y atractiva de un lugar, e incorporan mapas para ayudar a llegar a los lugares que proponen. La geosemántica puede considerarse similar a esta ordenación del conocimiento y la información; sin embargo, invierte la relación, y hace del mapa el soporte de la narración, para un amplio espectro de manifestaciones e intereses humanos, no sólo el turismo y los intereses especiales, sino el amplio espectro de manifestaciones que se pueden realizar respecto de los lugares.

Los Sistemas de Información Geográficos (SIG), desde un comienzo se han instalado como herramientas de referencia y apoyo para las tareas de varias otras disciplinas, como la medicina, la sociología, la antropología, la geología, el gobierno, etc. Pero tuvo que llegar el año 2005, con la salida a internet de Google Maps, y más aún luego, con el lanzamiento de Google Earth, para que dichos SIG, presentados en un esquema «amistoso» y social, se hayan hecho disponibles como parte del argot cotidiano de herramientas que los usuarios comunes y corrientes de internet tienen para potenciar sus actividades en la red. Se abre así la disponibilidad masiva de mapas digitales que entra a formar parte de los medios sociales en internet, generando la variante basada en la localización (locative based social media), con la implicancia de crear una nueva era $« p o s-S I G »{ }^{18}$.

La neogeografía puede entenderse como la popularización social del acceso a los SIGs ${ }^{19}$, entendidos ahora con el genérico de mapas digitales, desprendida de la complejidad y seriedad de la cartografía científica y administrativa, desplazada hacia el uso libre y cotidiano, que permiten realizar funciones como buscar una dirección, colocar una foto sobre un mapa digital, poner una anotación descriptiva sobre el mapa, enviar lugares, etc.

Uno de los primeros aspectos que cabe resaltar es, por tanto, la popularización de los SIG hacia servicios y funcionalidades de mapas web para ordenadores y móviles que permiten comunicar socialmente lugares y plantean de este modo la simplificación y caída de las exigencias científicas y/o administrativas con que se manejan los SIGs, hacia un principio básico y simple, que

\footnotetext{
18 «Locative media are digital media applied to real places and thus triggering real social interactions» Ver articulo «Locative media» en Wikipedia.

http://en.wikipedia.org/wiki/Locative media

La importancia de estos medios puede entenderse como un momento epocal que abre lo que se ha planteado como la era pos-SIG. Ver: HARVEY, F. (2013)

${ }^{19}$ Sin embargo: «Neogeography is not limited to a specific technology and is not strictly web-based, so is not synonymous with web mapping though it is commonly conceived as such». En: Neogeography, Wikipedia.
} 
es muy potente: los usuarios pueden anotar en el mapa y luego compartir con el mundo. El nivel de complejidad lógica (visual e interactiva) de dichas anotaciones, puede enriquecerse sin necesidad de especialización del usuario; las funciones son fáciles de usar, y promueven el acto de anotar dentro de la lógica web 2.0. Estos SIGs desnaturalizados por su fácil disponibilidad y carácter fluido, puestos a disposición masiva de la sociedad adquieren la denominación genérica de «mapas digitales» que usamos aquí, es decir, son expresiones de su popularización como servicios sociales de información, comunicación e interacción.

La neogeografía nace de este acto: la puesta en el dominio de las masas de internautas a nivel global de las herramientas de mapas digitales para su uso social. Es decir: la instalación del mapa digital en la constelación de los social-media.

Las distintas alternativas tecnológicas para georreferenciar, desde el acto más sencillo de enviar una dirección, hasta describir con datos enriquecidos un lugar y en fin, de hacer de los mapas electrónicos un recurso de la vida cotidiana, es un área de expresión social nueva para todos; es decir, lo valoramos en tanto es un fenómeno emergente. Consideramos que la georreferenciación social es otro de los factores que definen la neogeografía.

Por otro lado existe también la tendencia a «incrustar» recursos de mapas digitales dentro de blogs y sitios web de terceros, lo que se ha llamado mashup; se trata de una forma de compartir dichos recursos de mapas para los lectores de estos sitios web, ello puede verse enriquecido por diversos niveles de complejidad en las «incrustaciones». Esta tendencia también debe entenderse dentro del ámbito de la neogeografía ${ }^{20}$.

Otra forma de entender la neogeografía es a partir del concepto de «voluntariado cartográfico» ${ }^{21}$, esto se encuentra dentro de las tendencias denomina-

\footnotetext{
${ }^{20}$ Incorporamos dentro del término «mashups» la manipulación, que puede llegar a ser compleja y experta de las APIs. «El término implica integración fácil y rápida, a menudo usando varias API abiertas y fuentes de datos para producir resultados enriquecidos, que no fueron necesariamente el motivo original de producir la fuente primaria de datos». Ver artículo «Mashup» en Wikipedia.

http://en.wikipedia.org/wiki/mashup

${ }^{21}$ Cabe notar que este flujo de voluntariado cartografíco venía muy bien a la ciencia de los mapas, hacia el año 2007, M. F. Googchild hacía notar que la captura in situ de la información geográfica científica estaba en declive: «such volunteering appears to provide the only feasible solution to what is in reality a dramatic decline in the supply of geographic information worldwide. Mapping peaked several decades ago, and in many parts of the world, including some developed countries, the rate of production and updating is now substantially lower
} 
das de ciencia ciudadana, en la cual la comunidad científica busca hacer participar a la ciudadanía para realizar aportes de baja complejidad de datos científicos para determinados proyectos de investigación tal como los proyectos de Galaxy Zoo ${ }^{22}$. Del mismo modo del uso a favor de la ciencia y la cartografía de las anotaciones ciudadanas, en la cartografía participativa o mapeo participativo.

Como punto en común de todas prácticas de neogeografía, cabe notar el acto geográfico cartesiano de asociar coordenadas para un punto de referencia en un mapa digital. Por ello es que podemos decir que el orden de la georreferencia social es propiamente neo-geográfico y que la neo-geografía se refiere a las prácticas cartográficas sociales en internet.

Cuando decimos que la neogeografía deriva del acto cartesiano de apuntar coordenadas, establecemos una primera diferencia con el planteamiento de la geosemántica social. La geosemántica social se plantea poder levantar los sentidos del lugar, es decir, penetrar en una comprensión de cómo a través de las anotaciones sociales se construye una semántica del territorio, una narrativa, que es más que la suma de una anotación más otras sobre un lugar. La geosemántica social plantea la búsqueda de los componentes vivos capaces de dar significado e identidad a un espacio geográfico relevante para las comunidades humanas, constituyendo un aporte a la comprensión del mundo de la vida $\mathrm{y}$ de las instersubjetividades dentro y en torno del territorio y el lugar.

Cuando hablamos que la neogeografía se ubica en el orden de la georreferenciación, planteamos también otra diferencia cardinal frente a nuestra propuesta. Tal como se señaló anteriormente, la georreferenciación no constituye por sí un material interesante para la geosemántica social, es la anotación social que siembra sentido de lugar; la forma en que esta adquiere vida; las derivas que sigue en los medios sociales; su impacto y penetración en la formación de alternativas en un horizonte potenciado; en general, la manera en que se abre camino hacia los lugares físicos, es lo que resulta para nosotros relevante de una anotación.

La geosemántica social plantea la semantización de los espacios geográficos, de acuerdo a actos vitales que suceden en torno de determinado lugar; por tanto, más que georreferencias, lo que se está haciendo es una composición de

(Estes and Mooneyhan, 1994)». En: GoodchiLd, M. F. (2007). También véase artículo Volunteered_geographic_information en Wikipedia:

http://en.wikipedia.org/wiki/Volunteered_geographic_information

22 Por ejemplo la plataforma Galaxy Zoo, que solicita a los internautas con tiempo libre para que realicen observaciones astronómicas de carácter básico clasificando tipos de galaxias por su forma. Ver en: www.galaxyzoo.org. 
sentido, que puede penetrar aspectos afectivos vivos, energías emocionales y expresiones lúdicas, que se estructuran a partir de un imperativo narrativo del territorio, más que solo geo-locativo. La georreferenciación de aspecto cartesiano, que intenta dar significación a los espacios geográficos, se diferencia en grado de la geosemántica social, en tanto esta última se despliega como medio para producir el «campo de sentido» de los lugares, y en este acto lleva a cabo una función generativa emergente, que tiene grandes potenciales en la construcción territorial de los espacios geográficos mediante los mapas digitales. Esto se hace más dinámico aún al cruzar nuestro enfoque con los potenciales de la web semántica.

\section{II.1. Las plataformas}

Para profundizar en estas diferencias de enfoque entre la neogeografía y la geosemántica social, revisaremos algunas de las expresiones actuales que consideramos manifestaciones propias del concepto de neogeografía. Para ello realizaremos un muy breve análisis de las plataformas: Waze, Foursquare, y OpenStreetMap. Se examinará cada una de estas plataformas considerando antecedentes históricos, las características y funcionalidades; y se considerará el número de usuarios registrados.

Hacia el final haremos referencia a la participación de Google Inc. como principal proveedor de servicios de cartografía y mapas digitales con Google Maps y Google Earth.

Waze, Foursquare y OpenStreetMaps son tal vez los fenómenos más exitosos de la apertura de los mapas a los medios sociales. Su éxito puede ser medido por su permanencia, la cantidad de socios que han registrado o, para aquellas orientadas comercialmente (Waze y Fousquare), por el éxito de su modelo de negocios. Desde el punto de vista de nuestro enfoque tecnológico social es también relevante describir las arquitecturas de funcionalidades que le permiten tener versatilidad para responder a las necesidades de los usuarios.

\section{1.a. Waze «Evitando el tráfico juntos» ${ }^{23}$}

«Waze es la aplicación de tráfico y navegación basada en la comunidad más grande del mundo. Únete a los conductores de tu área que comparten el tráfico e información de ruta en tiempo real ahorrando todos tiempo y dinero en sus desplazamientos diarios» ${ }^{24}$ «Waze es una aplicación social de tránsito automotor en tiempo real y navegación asistida por GPS», «La colaboración

\footnotetext{
${ }^{23}$ Slogan del sitio web oficial: https://www.waze.com/es-419

${ }^{24}$ Ibídem.
} 
abierta en este servicio permite a los usuarios poder reportar accidentes, congestiones de tráfico, controles de velocidad, puntos de interés entre otros. El programa requiere una conexión de datos en el dispositivo móvil») ${ }^{25}$

Iniciada el año 2008, Waze es una red social abierta, que no requiere registro explícito; el hecho de bajar e instalar la aplicación en el aparato móvil crea el usuario y lo integra a la red de conductores en áreas locales, considerando la cercanía espacial como punto de cruce entre uno y otro usuario, puesto que un usuario puede ver a otro usuario si se encuentra conduciendo su vehículo en un sector donde el otro usuario ha realizado su anotación. Actualmente se encuentra implementada en 13 países.

Está dedicada a mejorar las condiciones del tránsito vehicular en las calles y carreteras. Esta plataforma se orienta a su instalación en dispositivos móviles (principalmente celulares de diversos sistemas operativos) y permiten anotar en un mapa mientras el usuario (denominado wazer) circula y testimonia una serie de características del flujo vehicular. Estas anotaciones pueden ser validadas por otros miembros de la red, con lo cual otros usuarios pueden establecer niveles de confianza hacia la veracidad y precisión de la información publicada. Existen también puntajes dados a quienes más anotan en la red, mediante los cuales los wazers adquieren niveles de prestigio. Es posible integrar las cuentas Waze con Facebook y Twitter.

Esta red social fue adquirida por Google Inc. en 2013, sin alterar el funcionamiento de la aplicación. Es evidente que con la adquisición de este tipo de servicio la compañía puede alimentar de información de tránsito en tiempo real a las principales ciudades del planeta, adquiriendo precisión en métricas de gran escala; de este modo adquirir conocimiento contextual de lugar a partir de sus millones de usuarios. «According to Yahoo! there were nearly 50 million Waze users as of June $2013 »^{26}$

Esta aplicación para aparatos móviles es ejemplo del poder de la cartografía social, colaborativa y en tiempo real. Desde nuestra óptica, Waze representa un faro en medio del océano de posibilidades; su eficacia en contactar personas que no se conocen y hacerlas interactuar de manera virtuosa, obteniendo a su vez rentabilidad, nos coloca ante el potencial de otras invenciones futuras que utilicen modelos similares en muchas otras actividades humanas que involucran desplazamiento espacial. Dar el poder de planificar con inteligencia territorial los desplazamientos es algo que la geosemántica social puede observar para obtener rendimientos propios.

${ }^{25}$ Artículo Waze en Wikipedia. http://es.wikipedia.org/wiki/Waze

${ }^{26}$ Ver nota anterior. 
Waze pertenece al orden de fenómenos asociados a la neogeografía, en tanto realiza la expresión cartográfica libre, voluntaria y colaborativa, que explota los potenciales de la georreferenciación y su combinación con datos en tiempo real de manera brillante para resolver un problema cotidiano.

\section{II.1.b Foursquare}

«Foursquare is a local search and discovery service mobile app which provides a personalised local search experience for its users. By taking into account the places a user goes, the things they have told the app that they like, and the other users whose advice they trust, Foursquare aims to provide highly personalised recommendations of the best places to go around a user's current location» ${ }^{27}$

Esta aplicación fue lanzada el año 2009 con el objeto de permitir a sus usuarios registrados anotar lugares tales como cafeterías, museos, cines, etc. Centrándose en compilar recomendaciones para dichos lugares. La plataforma insta a los dueños de locales a incorporar sus negocios al mapa, es decir: a su base de datos, que quedará disponible para que los concurrentes recomienden sus experiencias.

Los usuarios pueden entrelazar sus cuentas de Facebook y Twitter. Con lo cual potencia las anotaciones a través de redes sociales.

Este servicio está en constante transformación, una importante actualización; Foursquare 8.0, lanzada en agosto de 2014, ha eliminado algunas de las funcionalidades, las cuales han sido transferidas a un nuevo servicio creado llamado Swarm. Como resultado, el antiguo Foursquare ha devenido dos servicios distintos que, sin embargo, comparten algunas de las informaciones de cara a sus usuarios. Swarm ha tomado las funciones que permiten a un usuario saber dónde se encuentran otros usuarios de su red social, eliminándola de Foursquare.

Esta plataforma es un caso bienaventurado, a fines de 2013 este servicio contaba con 45 millones de usuarios registrados y su plataforma había sido traducida en 13 lenguas.

Para nuestro enfoque debemos considerar que este servicio entrega la posibilidad de anotar lugares de manera limitada, puesto que los lugares para anotar vienen predefinidos, siendo detectados y sugeridos de acuerdo a los desplazamientos y ubicación localizable de los dispositivos, pero también haciendo preguntas sobre tipo de lugar (cafeterías, museos, etc.). Es decir, los

${ }^{27}$ Artículo de DBpedia. Véase en: http://dbpedia.org/page/Foursquare 
lugares que aparecen en la plataforma, deben ser creados por un administrador previamente; por tanto, se ve limitada la libertad para señalar un lugar a gusto del usuario si dicho lugar no ha sido incorporado previamente.

Lo que está en el fondo de esta limitación es precisamente una restricción a la anotación de lugares. A pesar de permitir compartir lugares con la red social personal, estos lugares son elevados según criterios que mayormente apuntan a una visión comercial, donde el individuo es entendido como consumidor de distintos servicios, cercanos a su posición geográfica.

Siendo una plataforma altamente exitosa, con un avalúo en 2014 de 900 millones de dólares ${ }^{28}$ y 4 billones de anotaciones, es el mayor referente de anotación existente actualmente, marcando la senda de hacia dónde va la industria de servicios locativos.

Foursquare es una expresión perfecta de la Neogeografía; ofrece una mirada a los potenciales de anotación dentro de la lógica del mercado y con ello se ha transformado en un medio valioso para el análisis de los espacios geográficos comerciales actuales y potenciales. Y aún muestra muchas posibilidades para asistir a rubros específicos. En palabras de Gerson BELTRÁN (2014) «Cincuenta millones de usuarios diciendo dónde están, puntuando las Herramientas de Geolocalización Social, negocios y ofreciendo comentarios sobre los mismos es una cantidad de información muy importante para el geomarketing en el entorno del Big Data».

Desde la geosemántica social Foursquare es un gran aporte, su energía colaborativa y a la vez crítica en sus recomendaciones, nos muestra un camino amplio para pensar en sus posibilidades de funcionalidades interesantes desde el interés de información y conocimiento que nuestra disciplina propone.

\section{II.1.c. OpenStreetMap}

«OpenStreetMap lo crea una gran comunidad de colaboradores que con sus contribuciones al mapa añaden y mantienen datos sobre caminos, senderos, cafeterías, estaciones de ferrocarril y muchas cosas más a lo largo de todo el mundo.

OpenStreetMap valora mucho el conocimiento local. Los colaboradores utilizan imágenes aéreas, dispositivos GPS, mapas y otras fuentes de datos libres para verificar que los datos de OSM sean precisos y estén actualizados» ${ }^{29}$

\footnotetext{
${ }^{28}$ Véase: Yahoo Inc. reportedly in talks to buy location-based app maker Foursquare for US\$900 million.

http://business.financialpost.com/business-insider/yahoo-inc-reportedly-in-talks-to-buy-location-based-app-maker-foursquare-for-us900-million? 1sa=47d9-a87b

${ }^{29}$ Véase: http://www.openstreetmap.org/about
} 
OSM tiene casi 2 millones de usuarios registrados y 4.552.192.498 de puntos GPS registrados a febrero de $2015^{30}$. Se trata de una entidad activa que tiene diversas representaciones internacionales con un modelo open; es decir, de datos abiertos sobre calles. La filosofía de datos libres en la que se basa OSM implica una separación estricta respecto del uso de fuentes de mapas provistos por Google, puesto que su carácter propietario podría poner en riesgo la solidez de $O S M$ ya que sus datos podrían ser objeto de demandas legales referidas a la propiedad intelectual sobre cartografía y métodos de geo codificación, etc.

$O S M$ es, por tanto, una plataforma que sí permite la anotación libre en una lógica reflejo de la tecnología social Wiki; se plantea como el sitio donde las ciudadanías del mundo pueden describir sus espacios geográficos de manera abierta y de este modo hace crecer su base de datos de lugares. Su modelo no comercial se basa en fundaciones que participan a niveles nacionales y se hacen cargo de la representación de la aplicación. Este modelo permite generar una autoridad a cargo del cuidado de las cartografías anotadas, con lo cual todo el sistema queda a manos de dicha autoridad, la cual genera alianzas con entidades poseedoras de cartografía para compartir, bajo el principio open. De este modo, la cartografía oficial aportada, por ejemplo, por el Ministerio de Obras Públicas de Chile se coloca como anotación precedente y «de autoridad» frente a la anotación de una persona común con algo que decir sobre el mapa.

Cabe notar del mismo modo la importancia que OSM plantea frente a la verificación del lugar, el dato cartográfico anotado debe tener un valor veritativo. Y debe tenerlo para poder entregar información fidedigna a quienes pasan por esta plataforma para buscar información cartográfica y mapas de lugares. La noción de veritatividad, la búsqueda de la anotación verídica, tiene la misma debilidad conocida por la lógica de las Wikis, y es que el sistema hace posible a cualquier persona anotar, facilitando actos de desinformación y comportamientos vandálicos sobre los datos cartográficos. Sin embargo, al igual que la Wikipedia, OSM tiene la solvencia de anotaciones suficiente para subsanar estos ataques malintencionados con información cartográfica válida.

La plataforma $O S M$ tiene cualidades que facilitan las anotaciones cívicas y colaborativas, lo que interesa a nuestra disciplina y por ello se subraya su importancia para nuestros propósitos de investigación. Sin embargo, desde el punto de vista que propone la geosemántica social, la anotación de lugar incluye como parte del campo semántico válido a la anotación creativa, que involucra ficción, mitología y literatura, pero también aquella que se presta para

${ }^{30}$ Véase: http://www.openstreetmap.org/stats/data_stats.html 
la doble lectura (antagónica, litigiosa) de los territorios. En nuestro enfoque la validez veritativa y la validez creativa se colocan juntas y son activadas en dinámicas sociales que impactan sobre lugares geográficos; el significado que emerge, las cualidades y atributos identitarios pueden trascender y convertirse en realidad como sentido del lugar.

La neogeografía acoge a $O S M$ dentro de su lógica: la cartografía voluntaria, la convocatoria a la colaboración, el uso para consultas fáciles sobre lugares, todas estas características son manifestación de la libertad para generar contenidos cartográficos sin ser especialistas en cartografía, la gente tiene un canal para expresar y comunicar lugares. Aunque es posible que un exceso de oficialidad devuelva a OSM dentro de la esfera de la cartografía clásica moderna, y que su apertura a la ciudadanía implique su uso jerárquico basado en la autoridad. Si la autoridad significa prestigio cartográfico es posible que OSM puede sobrealimentarse de ese espíritu, limitando el sentido de participación ciudadana a una actividad sucedánea de ciencia cartográfica ciudadana, donde el ciudadano es el productor pero la autoridad (bajo la forma de un censor o editor) es la que otorga la validez a su anotación.

Al hacer este análisis de las tres plataformas más destacadas de servicios de cartografía y mapas digitales hemos comparado a la Neogeografía con la geosemántica social, para establecer las diferencias y las similitudes. Pretendemos demostrar que la Neogeografía se halla involucrada actualmente en la creación de anotaciones sobre lugares (lo que hemos llamado georreferenciación social) bajo un prisma comercial que debe ser visto también desde el punto de vista del interés de las empresas cuyas ganancias están determinadas por el conocimiento de patrones del consumo localizado de las personas, con sus recurrencias y muchas otras métricas de alto valor comercial.

Tanto Waze como Foursquare tienen vocación comercial neta, orientada a facilitar comportamientos de consumo, lo cual se hace no sólo a través de la recomendación de lugares, sino también mediante la minería de datos que permite establecer patrones de desplazamiento asociado a las potencialidades de incentivo del consumo. OSM, por el contrario, tiene una aspiración cartográfica, la de prestar un servicio de mapas y cartografía válido y confiable para la consulta de los usuarios en línea, facilitando la anotación de lugares y tratando de remediar de la manera más rápida los errores o faltas que se puedan hallar. Este objetivo cartográfico confiable pertenece al ámbito de la ciencia ciudadana que ya hemos mencionado, se trata propiamente del voluntariado cartográfico en el cual la persona común puede convertirse en parte de un esfuerzo universal por el mejor conocimiento del mundo. 
Sin embargo, OSM sólo facilita la anotación plana de información cartográfica en el mapa, la cual es publicada una vez que editores realizan su validación y publicación, pero no permite dinámicas sociales «en el mapa», tales como anotaciones y comentarios sobre anotaciones de manera interactiva; por tanto, no permite la discusión «en el mapa» sobre los puntos de vista de los lugares planteados. Falta, sin embargo, un estudio de geosemántica social sobre casos paradigmáticos de anotaciones litigiosas que este artículo en específico no pretende cubrir.

La Neogeografía se plantea por tanto como algo que llama a su uso colaborativo, algo divertido, pero que puede ir más allá de la diversión para convertirse en un aporte ciudadano a la construcción de un conocimiento del espacio geográfico. Ninguna de las plataformas que hemos revisado pretende comprender el territorio, ni encontrar el sentido del lugar. De hecho la vereda comercial de estos servicios permite construir un tipo de lectura territorial del consumidor, un territorio del consumidor, o mejor dicho, del prosumidor ${ }^{31}$, en el sentido de que este consumidor produce la información crucial para alimentar a las empresas y sus intereses en el mercado, que permiten activarlo como consumidor y productor de necesidades en la racionalidad del capital. En este territorio del consumidor, la potencia creativa y crítica propia de las redes de ciudadanos se halla ausente. De este modo podemos decir que la neogeografía puede ser descrita dentro del ámbito del mercado, vistas las plataformas más exitosas tales como las analizadas. Si los grupos de usuarios son entendidos también como ciudadanos surgen otras dimensiones de anotación que no están presentes en la orientación de Foursquare ni Waze, aunque sí de OSM; sin embargo, su objetivo de cartografiar positivamente también puede ser entendido desde una perspectiva de prosumidores, orientado al uso referencial de sus mapas.

OSM resulta, pues, un modelo base de la anotación ciudadana; sin embargo, restringida por una lógica de mostrar el mapa integrado ya con sus anotaciones. Las anotaciones no son interactivas, si hacemos clic sobre ellas no surge metadato alguno. Por ello la búsqueda de cientificidad de este tipo de Neogeografía que puede identificarse con $O S M$, si bien abre un espacio para la anotación ciudadana, no facilita la construcción de significados sobre esos lugares y de este modo es tierra pobre para que se desarrolle el sentido territorial que nos convoca.

${ }^{31}$ Artículo Prosumidor en Wikipedia. http://es.wikipedia.org/wiki/Prosumidor 
II.1.d. Sobre Google Inc. y sus servicios cartográficos y de mapas digitales

De manera especial cabe hacer mención de los servicios de mapas y cartografía de Google. En primer lugar, respecto del tamaño global de esta compañía, podemos decir que es en sí problemático, desde el punto de vista de sus usuarios, de gobiernos, de varias disciplinas; nos resulta una empresa que tiene incidencia en la forma en que el mundo se viene desarrollando hace más de una década. Su masividad es problemática puesto que involucra una base de datos en la que una gran parte de la humanidad está implicada, existiendo problemas respecto de sus políticas de privacidad, sus prácticas de análisis de datos y comercialización de dichos análisis. Por su tamaño y por su penetración esta empresa es importante y muchas veces posiblemente determinante en la toma de decisiones de las personas a diario.

En el ámbito específico de la cartografía y mapas, tanto Google Maps como Google Earth son referentes mundiales. Más adelante se hará mención de la importancia de estos programas según se ha desarrollado nuestra propuesta desde el año 2005 en adelante. En este momento haremos relación de su importancia como fuente privada pero gratuita de datos de cartografía, mapas e imágenes satelitales.

Google posee imágenes satelitales relativamente actualizadas de todo el planeta, y también construye una base de datos de fotos de calles (Streetview), de las principales ciudades del mundo. Toda esta actividad cartográfica puesta a disposición de sus usuarios permite generar una gran cantidad de información relevante desde el punto de vista de la geosemántica social, puesto que da paso a la expresión de los lugares, tanto a partir de la lógica comercial de inscribir locales comerciales en sus mapas, sirviendo como especie de guía comercial como expresión de la lógica de anotar (proponer) un lugar de servicios (negocio, comercio, lugar público).

A pesar de esta limitación en general, los servicios de Google sí generan datos relevantes para la investigación y desarrollo de la geosemántica social, especialmente como se verá más adelante porque hace disponible de manera directa el compartir lugares y generar información geográfica, la que puede perfilarse como información territorial que entrega materiales para dar significado a los lugares, entregando componentes distintivos valiosos para entender y levantar sentidos del territorio. Se hace patente que su limitación es el carácter propietario, que no asegura la permanencia de las fuentes de mapas e imágenes satelitales, ni su actualización, siendo potestad de la compañía cambiar o alterar la naturaleza y las premisas sobre las cuales el usuario común ha estado o cree haber estado anotando sus mapas. 
El cambio imprevisible en las políticas de Google no es algo que esté bajo el control de los cientos de millones de usuarios. Con esa objeción implicamos también la existencia de una duda existencial para los datos anotados, respecto de qué tan libres son para ser comunicados, respondidos y dinamizados, teniendo un límite en dichas políticas mutables del propietario Google Inc.

Un caso relevante para nuestro enfoque es la desaparición de Panoramio, la funcionalidad de poner nuestras fotos en álbumes georreferenciados visibles en Google Earth. El poder de esta aplicación es notorio, ver fotos que aumentan nuestros conocimientos contextuales de un lugar que vemos sobre un mapa digital o globo virtual. Su desaparición puede significar muchas cosas; sin embargo, es posible que el aumento de los teatros de guerra en nuevas regiones y países haya puesto a este servicio en la línea de los intereses estratégicos de los involucrados. Este alcance de por sí es demostración del poder de Panoramio: actualmente podemos contemplar las fotografías de la milenaria ciudad de Alepo en Siria y testimoniar la lamentable pérdida histórica y patrimonial.

Considerando este análisis crítico de las plataformas mencionadas, referentes principales de georreferenciación social, debemos hacer notar que todas estas plataformas sí inculcan, facilitan y producen un acercamiento de las personas con la idea de anotar lugares y comunicar lugares, que su práctica permite la familiarización con la cartografía, lo cual constituye una propiedad crucial de las principales plataformas que están disponibles para los usuarios corrientes; y que además permiten generar distintas dinámicas e interacciones. Los grandes números de personas involucrados en estos sistemas son manifestación de la masificación de la práctica de anotar y los potenciales de esta situación tecno-social emergente.

\section{TEORÍA GEOSEMÁNTICA SOCIAL EN CUATRO TEXTOS}

En diez años se han realizado varios trabajos tomando el marco teórico conceptual de la geosemántica social, como instrumento para producir resultados, experimentando su aplicación en diversas áreas problemáticas tales como la historia, la cultura, los nuevos medios, los temas estratégicos y de geopolítica. Después de lo anteriormente expuesto, corresponde realizar una recapitulación para comprender el vector de sentido en el tiempo de nuestra propuesta disciplinaria; planteo realizar una revisión de este trabajo desde una lectura evolutiva de los escritos más destacados para el desarrollo de la teoría y la práctica investigativa tal como la entendemos hoy. Tomaremos cuatro textos de los años 2005, 2006, 2008 y 2013, los cuales son representativos de tres momentos en su modelamiento, que nos permiten abrir un camino armonioso 
hacia su constitución actual, en el caso del escrito de 2006, este había permanecido como apunte publicado sin difusión en una página de internet, cuya relectura conecta la visión de 2005 con las siguientes publicaciones.

\section{III.1. Geosemántica: el sentido de la Tierra (2005)}

En primer lugar, con la publicación de «El mundo según Google: Google Earth y la creación del dispositivo geosemántico global» ${ }^{32}$ en la revista chilena AAinteligencia en septiembre de 2005, se trataba de responder con una visión antelatoria, un posible camino de desarrollo tecnológico para los globos virtuales, entendidos como navegadores integrales de contenidos geolocacionados. De este modo el inmenso poder de la herramienta Google Earth se transformó en la base conjetural para pensar arquitecturas virtuales para generar una hiper-enciclopedia, que permitieran navegar a través del planeta, dando acceso a una visión contextual del espacio geográfico dónde está localizada y asociada una entrada semántica al sistema, una pregunta a un buscador.

Presentamos la idea de una web geosemántica social global, un navegador enciclopédico actualizado en tiempo real de todos los contenidos societales, pensada como agrupación virtuosa de ontologías, construidas socialmente en el rodaje, cubriendo un conocimiento de lugar social, constantemente actualizado, capaz de conversar en diálogo fluido con usuarios virtuales y personas, constituyendo un prototipo conceptual inicial de una inteligencia artificial social con sentido de lugar.

La argumentación de este texto considera líneas sobre un proyecto de Geosemántica de Canadá para establecer una distancia explícita respecto de nuestra visión geosemántica societal expuesta en esa publicación. En la propuesta el eje es el tipo de información societal asociada a un lugar: «...[1a] Web GeoSemántica Global permite darle a esa información una ubicuidad espacio temporal que aumenta considerablemente la capacidad de comprensión de dicha información. Ocurre en efecto una transformación radical de la tendencia filosófico política a la des-territorialización hacia una re-territorialización, que no atañe solamente a las informaciones sino, y de manera más relevante aún a los sujetos que despliegan sus intereses y estrategias en el mundo». Aquí se hace notar la orientación del enfoque teórico conceptual que en un extremo apunta a la dimensión teórica y filosófica política.

El artículo es una especie de manifiesto precursor en su planteamiento, que exalta la herramienta «web geosemántica global» como recurso de tecnología transformadora, como la posibilidad de construir una gran enciclopedia con

${ }^{32}$ En: https://sites.google.com/site/geosemanticagearth/ 
todos sus datos de carácter semántico asociados a lugares en tiempo real. El mismo tiene un sentido de urgencia respecto de los sucesos emergentes que estas tecnologías cartográficas plantean en adelante, al hacer asequible a las mayorías de una herramienta de inteligencia geográfica humana, que potencialmente sería alimentada en tiempo real. Citamos palabras de la época: «Estamos asistiendo, de la mano de Google Earth al nacimiento de una nueva forma de percibir el espacio, que afecta al mismo tiempo al espacio virtual y al espacio real de nuestro planeta, así como constituye un nuevo plano mental para los usuarios, individual y también como colectivo. Para entender el nivel de penetración de esta nueva lógica que comienza a penetrar nuestras mentes, hay que entender el fenómeno de lo masivo».

Hay entusiasmo y precaución en esta cita, una percepción latente de un momento en la historia tecnológica de la cartografía, la imagen satelital y la ubicuidad locacional. Se trata de un texto encendido por un «Euréka!» del autor ante una visión clara de un ámbito capaz de tener un gran impacto sobre la sociedad.

En general estos textos teóricos sobre geosemántica social están marcados por el entusiasmo, aunque con variaciones, pues esta visión inicial es luego puesta en suspensión, pasando nuestro foco hacia ámbitos distintos de la original visión de una enciclopedia societal alimentada en tiempo real sobre coordenadas reales y contextuales.

\section{III.2. Geosemántica: el sentido de la Tierra (2006)}

Se incorpora aquí un texto escrito el año 2006; este había sido puesto en internet a modo de borrador y al releerlo entiendo que ahora adquiere sentido para conectar los textos publicados de 2005 con el siguiente de 2008, de este modo se podrá entender el paso desde una búsqueda más semántica y de ontologías, hacia una más territorial, la búsqueda del «sentido de lugar» preformada en este texto conecta también a lo que se publicaría ocho años más tarde, en 2013.

Geosemántica quiere decir «Sentido del Mundo», es decir, la conjugación entre el ámbito semántico, entendido como la producción de significado y sentido (semantikos: significativo, semainein: querer decir, significar); y, Gea, la Tierra. A pesar de tratarse de un término ideado para denominar a ciertos sistemas de bases de datos de geociencias, consideramos que su etimología implica un rango más amplio de dominio, que lo despliega desde la especificidad de las geociencias hacia una base de datos abierta e infinita de referencias geográficas informativas, comprensivas y contextuales, descritas espacial y temporalmente (diremos también, más adelante, que incluye la representación 
de una quinta dimensión en el sentido). Geosemántica refiere a cualquier acto de geo-referenciar, es decir, de otorgarle a un dato-información, una posición geográfica y espacial asociada (lat. long. alt.), describiendo así, en conjunto, una unidad comprensiva entre Lugar y Significado. Ello a través de la agregación de datos informacionales en torno de un Nodo en la Red, que permite coordinar y vincular significados con lugares.

Una cualidad significativa que otorgamos a la geosemántica es la capacidad de entender este ordenamiento geosemántico de manera trivial y con un uso popularizado. Por ejemplo, la capacidad más vernácula de postear fotos en la Red, indicando los lugares en que fueron tomadas; la foto es el dato y los datos asociados son metadatos con la cualidad (latitud, longitud, altitud) que les otorga la dimensión geoespacial.

Todo esto viene a ser posible a partir de la implementación a mediados de 2005 del programa Google Earth por Google Inc. Cualquier evento puede ser publicado (posteado) en un planeta Tierra virtual que reproduce fotos satelitales de diversa resolución; un espacio de superficie de contornos tridimensionales, y un sistema de navegación en base a comandos aéreos (volar a, inclinación, altura de la visión, etc). Google Earth es la primera Matriz Abierta de información geosemántica. Y allí es donde la gente empieza a postear su información geosemántica.

Pero para considerar la construcción de esta base de datos es preciso plantear la expectativa de que el llenado de esta base de datos se desarrolle de manera similar a la usada en la Wikipedia, es decir a partir de la colaboración abierta. Pero una colaboración que exige seriedad, honestidad y compromiso, además que una capacidad sintética que no cualquiera posee, la capacidad de definir conceptos de acuerdos a reglas semánticas específicas, que permitan escalar en la construcción de ontologías geosemánticas libres.

Por ello, lo realmente impresionante de la propuesta geosemántica, es que nos lleva a plantear el camino hacia una quimera que despunta en nuestros horizontes tecno-informáticos, la Inteligencia Artificial colectiva, es decir la construcción pública de un repertorio creciente de conocimiento preciso y perfectible sobre el mundo, enlazado por la Red de Redes, disponible y abierto, y construido en base a una descripción semántica rigurosa que permite diálogos activos hombre-máquina. El Proyecto de web semántica es capital para comprender el optimismo de quienes apostamos por la geosemántica. La Web 3.0 es la propuesta, que lleva casi 10 años planteando el W3C, cuyo líder Tim Berners Lee defiende, como Proyecto de una Web Inteligente, e inteligente cada vez más «de verdad». Pero la Web Semántica requiere ser construida, y 
actualmente hay muchos trabajando en construirla, además de existir ya sistemas de Web Semántica que organizan la información de grandes empresas del planeta.

Para la construcción de la Web Semántica la dimensión Semántica es clave. Implica la precisión de las estructuras sintácticas y gramaticales del lenguaje, de manera de producir descripciones simples, entendibles por humanos y máquinas. Cada información contiene metadatos, es decir, datos asociados que contextualizan, que explican y hacen comprensible la información en un dominio de conocimiento. De esta manera, cada descripción singular enlaza en la Red con un Nodo de articulación de lenguaje humano a partir de los contenidos disponibles en un Sistema de Sentido dentro de un Dominio de la Realidad, dentro del cual se hace conocimiento geosemántico activo.

\section{III.2.a. S.I.G., Topologías de la red y geosemántica social}

Actualmente los SIG (Sistemas de Información Geográficos) empiezan a poblar los lugares comunes de muchas actividades de la Sociedad Red. Estos sistemas permiten la organización de la información de manera sistemática de modo que podemos contar con ella como información sistematizada para llevar a cabo operaciones sobre los sistemas sociales. Esta nueva forma de relacionar la producción social con la geografía, de manera cada vez más masiva a partir de los SIG, nos hace prestar atención a que el tipo de información que la geosemántica puede llegar a manipular depende de una convergencia entre los SIG, los aparatos de producción y la sociedad. Los SIG instalados para mejorar las capacidades de administración y operación cotidianas de las diversas áreas de trabajo están diseñados para manipular información geográfica de acuerdo a las necesidades de cada área donde son implementados; siendo así parte del proceso de automatización informático.

Si bien los SIG abstraen la espacialidad geográfica, es decir, sistematizan geo-información en matrices de datos binarios; en esa operación también abstraen, mediante la diagramación de la información, el sentido geoespacial de referencia que contextualiza la posición del dato. Esto es, el sentido de lugar que permite territorializar el conocimiento, rescatándolo del no- territorio puramente virtual.

Igualmente consideramos a las Topologías de la Red, que diagraman los flujos de valores, información, bienes, servicios; así como el entramado biótico ambiental y los seres humanos, como parte de un movimiento virtualizador-abstracto del territorio de producción de los conocimientos e informaciones. Actualmente la Arquitectura Red define de una nueva manera las divisiones y uniones entre territorios geográficos, donde habitamos. Los Mapas de 
Redes que describen la Topología de la Red se centran en los diversos flujos, los canales, los nodos de producción y consumo, los nodos que deciden sobre la conexión/desconexión de los territorios, etc. Todo ello en base a un automatismo global orientado por los criterios de ganancia económica. Al ser georeferenciados estos flujos se convierten en territorialización de los flujos, en un plano explicativo que une el significado y el territorio.

El orden geosemántico otorga la georreferenciación comprensiva y contextual a los bit y bytes en circulación por el éter informacional, precisamente otorgándoles el sentido de lugar, es decir la asociación a un espacio de ocurrencia: un trayecto de derivado financiero, una reserva de hidrocarburos, la ubicación de un servidor, las redes de fibra óptica, los sectores de alto/bajo consumo de bienes y servicios, etc.

La dimensión geosemántica es planteada aquí como una construcción colectiva abierta, que tiene en Google Earth una herramienta para empezar a realizar georreferencias, empezar a poblar de contextos el mapa de la tierra y dar comprensibilidad a los «por qué» de nuestros territorios.

\section{III.3. La ecuación geosemántica (2008)}

El siguiente ensayo, escrito y publicado tres años después, entre los años 2007 a 2008, que fue solicitado por Media Lab Prado, laboratorio multimedia del Ayuntamiento de Madrid para su Segundo Encuentro Inclusiva-Net, propondrá enfocarnos en las consecuencias de realidad de actos cartográficos hipotéticos que se han hecho posibles gracias a la expansión de la facilidad para anotar en mapas y globos virtuales; este hecho abre el poder cartográfico agencial expresado en recursos de la Web 2.0, tomando en consideración sus eventuales consecuencias en la percepción y apropiación de los espacios en el nivel semántico interactivo mediante el despliegue de la agencialidad cartográfica.

Este texto se titula «Tierra sentido y territorio: La ecuación geosemántica» ${ }^{33}$; aquí se plantea la centralidad de un agente cartográfico diferencial, que se ha apropiado del poder de anotar, votar o afiliarse a mapas digitales. Para ello se tomaba el fichero *. $\mathrm{kml}$ de Google Earth, como recurso facilitador de anotaciones en mapas, realizando un análisis potencial de la autoría y autoritatividad de los espacios geográficos anotados y puestos en circulación. Este abordaje consideró la inclusión de la ficción y de la artificialidad, como esfera humana que es en adelante partícipe solidaria en la producción de una conciencia de lugar, proyectando una escalada de paradojas planteadas, que

${ }^{33}$ En: http://www.aainteligencia.cl/?p=133 
desde el nivel individual ascienden hasta alcanzar el nivel geopolítico, poniendo en juego la definición del territorio oficial y dando espacio para nuevas realidades cartográficas intersubjetivas.

La posibilidad de anotar y publicar en mapas dentro de la lógica Web 2.0 desencadena consecuencias conjeturales que tocan los ordenamientos territoriales estatales y por ello su potencialidad adquiere carácter estratégico territorial. La ecuación que articula el potencial comprensivo plantea que: TIERRA + SENTIDO = TERRITORIO. Su despliegue perfila efectos de realidad especulativos, los cuales sin embargo, abren la posibilidad de que dicha capacidad de producción social cartográfica sea empoderada por sujetos autores y sujetos agentes, que impulsen fenómenos de toma de conciencia de los lugares y de este modo generen consecuencias sociales y políticas sobre la realidad. Esta ecuación «...describe el proceso de territorialización relativa, es decir, el acto de dar un sentido a un lugar; simplemente otorgar contenido y coordenadas a un $\mathrm{kml}$. Este sentido puede ser mínimo (un punto del espacio marcado con un título y una breve descripción) o intensivo (un territorio volumétrico, con maquetas virtuales, noticias en tiempo real, palabras claves intensivas, etc.)».

La Web 2.0 como ámbito multimedia y comunicativo, permite colocar a los mapas al alcance de los grandes números de usuarios, hacia las masas que ponen en movimiento nuevas dinámicas sociales: «...cuando hablamos de masa crítica de afiliaciones al $\mathrm{kml}$, debemos comprender el poder de las redes sociales para desenvolver fenómenos de masividad inusitados». En este sentido se hace exposición de lo que se entiende por la neogeografía como el concepto que aúna ambos: la internet social y los mapas, el que permite expresar la geosemántica social con «...una ecuación mínima sobre la construcción social de contenidos geográficos».

Si en el texto de 2005 se buscaba una construcción experta de una web geosemántica global, en 2008 la semántica resulta simplificada para comprender la expresión diversa que surge de la Web, cada vez más social en el movimiento 2.0; ya no se trata de ontologías integradas sino de expresividad y socialización de anotaciones en mapas; lo semántico es la anotación y la capacidad de crear sentido en un lugar mediante los mapas digitales.

La geosemántica propuesta se adapta a las condiciones de la Web 2.0 como el espacio virtual donde converge la comunicación humana conectada, pero al asumir la Web 2.0 acepta también el comportamiento caótico y las paradojas del mundo virtual; con ello se adelanta a incorporar la ficción, el artificio, el mal entendido y el accidente como material de su comprensión. 
Ambos textos de 2005 y 2008 han tenido una repercusión visible en el mundo académico. La existencia de citaciones en tesis doctorales y otros artículos demuestra que la teoría geosemántica social ha tenido una recepción positiva dentro de las comunidades de investigadores, lo cual es señal que se ha logrado difundir y llegar a personas que pueden usar el conocimiento puesto a su disposición.

\section{III.4. Más allá del sentido de lugar (2013)}

En cuarto lugar nos movemos hacia el concepto de sentido de lugar como problemático en sí; planteando un «más allá del sentido de lugar», remontando este concepto hacia sus orígenes en los dioses lares, los espíritus de lugar y los penates de la Roma antigua. Se presenta la evolución de un concepto de «sentido de lugar» hasta hoy adaptado a las necesidades del mercado inmobiliario operando como refuerzo estético narrativo a proyectos de nuevos espacios arquitectónicos, urbanísticos, paisajísticos o de usos especiales de preservación.

El ensayo donde esto queda planteado se denomina «Más allá del sentido de lugar. Geosemántica social, ciencia del territorio» ${ }^{34}$ y se publicó en la revista electrónica chilena Escáner Cultural en julio de 2013. Este texto es el resultado tanto de una ampliación del enfoque teórico hacia el valor territorial del «sentido de lugar» como operador comunicativo, como de un giro pragmático de la investigación hacia el diseño y la modelación de dispositivos de geosemántica social, mediante el cual se han desarrollado un grupo de arquitecturas orientadas a administrar datos territoriales, estructurados de acuerdo a nuestro marco teórico conceptual.

El texto va directo a la cuestión del territorio como apropiación identitaria de las comunidades. Usando los planteamientos de 2008, a partir de la «ecuación geosemántica», la posibilidad de «hacer hablar» al territorio a través de sus lugares de acuerdo a un criterio expresivo comunicativo orientado a comunicar socialmente los lugares. En esta lógica se hacen relevantes aquellas anotaciones sobre mapas que generan filiación o rechazo, que comunican geosemántica social. Es decir: «sentido de lugar» anotado en mapas; difundido a través de los medios y redes sociales, donde la anotación adquiere un devenir de probabilidades de impacto y recepción en el mundo, especialmente en el lugar que establece una partícula de identidad que agregada a otros lugares también anotados conforman el territorio con valor social-comunitario.

Los procesos de empoderamiento de herramientas cívicas y de toma de conciencia del poder territorial local, en diversas partes del mundo, se encuentra

${ }^{34}$ En: http://revista.escaner.cl/node/7137 
entonces con una generalización del uso de los espacios geográficos significativos, como eje de las cuestiones del poder. El territorio entonces se transforma en una unidad corporal, un personaje que puede identificarse con una visión constitutiva del lugar a través de la geosemántica social. Este proceso de constitución identitaria del territorio, como movimiento en la sociedad contemporánea, junto a las herramientas de mapas digitales y el marco teórico que planteamos constituye un inmenso potencial para plantear herramientas que agreguen funcionalidades y dinámicas a la producción universal de sentido de lugar.

En adelante se abren una serie de desafíos para la relación entre mapas digitales y sociedad; el desafío que emprende la geosemántica social es investigativo práctico. De este modo entramos a exponer algunos principios sobre los cuales nos encontramos elaborando arquitecturas de servicios, que han sido pensados hacia la gestión territorial dando fuerza al componente comunitario que permite que el edificio modelado sea capaz de generar «sentido de lugar» visual e interactivamente frente a sus usuarios.

\section{COLOFÓN}

La teoría geosemántica social adquiere desde el año 2013 una misión investigativa práctica: facilitar y potenciar la relación territorial entre mapas digitales y sociedad, utilizando como eje al concepto de «sentido de lugar», que se eleva al estatus de guía paradigmática en el estudio, asistencia y composición de los espacios geográficos significativos, mediante sistemas digitales multifuncionales al servicio de actores y agentes interesados.

Sin embargo, para poder crear sentido de lugar se requiere una metodología propia que es de base cualitativa e informacional, que utiliza una lista de diversos métodos y técnicas que damos a conocer aquí:

$\checkmark$ Construcción de un mapa de referencia inicial,

$\checkmark$ Búsqueda de bases de datos interinstitucionales y organizacionales,

$\checkmark$ Diálogo de necesidades y diagnóstico organizacional,

$\checkmark$ Técnicas de levantamiento de información institucional,

$\checkmark$ Entrevistas individuales y grupales,

$\checkmark$ Trabajo participativo sobre mapa de referencia,

$\checkmark$ Técnicas de análisis de discurso.

$\checkmark$ Tratamiento y combinación de bases de datos

Todas estas herramientas investigativas conforman el cuerpo metodológico de la geosemántica social. Debemos mencionar que la arquitectura digital que estamos desarrollando como modelo comercial se encuentra en proceso para ser patentado. 
Queremos ahora explicar cómo opera el «sentido de lugar», la clave que activa y da vida al vínculo entre mapas digitales y sociedad.

El sentido de lugar es un dispositivo discursivo visual que permite ordenar la información geoespacial de acuerdo a referencias de apego, valoración y sucesos socialmente significativos; de este modo es posible hacer inteligibles los lugares en un marco de contextualización activa en el mapa que se traduce en asociaciones mentales virtuosas para comprender un territorio.

Para construir «sentido de lugar» se requiere la convergencia de dos principios axiales en nuestra visión disciplinaria: el principio de la participación y el principio de la narrativa.

La participación tiene su origen y relevancia en el nivel político de los intereses comunitarios y locales. Las causas y movimientos sociales son expresión desbordante de esa participación que en gran cantidad de ocasiones es totalmente local. Para el proceso de investigación y estructuración territorial la participación se traduce en el carácter abierto e inclusivo, tanto en el levantamiento, estructuración y composición de la información territorial.

La narrativa en el sentido mínimo significa cuento, historia, narración, y en fin comunicación con sentido; en este sentido hacemos uso del «paradigma narrativo ${ }^{35}$ que dentro de un sistema comprensivo abre el camino a la capacidad de ver con nuevas perspectivas lo mismo que tenemos enfrente, enriqueciendo la capacidad de juicio y valoración sobre las cosas. Pero para nuestro propósito disciplinario, la narrativa es adaptada hacia el universo territorial de la geosemántica social.

La narrativa organiza y potencia el carácter comunicativo de cada una de las instancias que componen la información territorial a considerar. Estas instancias se transforman de este modo desde ser un dato georreferenciado en un SIG a convertirse en una instancia que constituye una historia de por sí dentro del sistema cada instancia territorial es construida de manera narrativa; es decir, como frase que cuenta una historia localizada que permite generar un agregado de instancias narrativas que son mucho más que la suma de las partes. Estas historias son a su vez instancias del sistema y lugares geoespaciales que se cruzan y superponen en interacción, se ubican más lejos o más cerca de otras historias, que se oponen o se suman, se potencian o se confrontan.

El principio narrativo pone en juego dinámico las pequeñas historias que el territorio engendra como lugares y que a su vez permiten dar coherencia e

${ }^{35}$ Véase artículo «Narrative paradigm» http://en.wikipedia.org/wiki/Narrative_paradigm 
identidad al territorio. Sin el componente narrativo las instancias de información territorial son entidades pasivas a la interacción con otros lugares, limitándose a ser simples cruces de variables. Con este tipo de información no se puede decir que estemos representando un territorio, sino tan solo un espacio geográfico significativo. El poder narrativo permite un alcance intelectivo con referencia social y humana y convierte esos espacios en territorios inteligibles y además amables, puesto que buscan ser leídos, buscan contar sus historias y provocar asociaciones mentales virtuosas que lleven a una mejor gestión y a mejores decisiones territoriales.

El sentido de lugar como idea fuerza de nuestra teoría desde el año 2006, queda ahora instalado como el eje del dinamismo de la geosemántica social, tanto en el nivel teórico - conceptual como práctico. El conocimiento vertido en este artículo es un aporte del autor para que fructifique entre aquellos que han sintonizado con su planteamiento y su propósito, tanto en el ámbito académico, como también en el ámbito de desarrollo y aplicación práctica y tecnológica.

Dicho esto sólo queda hacer notar que nuestra disciplina encuentra su utilidad en un mundo en proceso de destrucción acelerada por el «cambio climático», donde todo parece indicar que es mediante un mayor empoderamiento local de las poblaciones y los territorios, el medio de hacer de nuestro planeta un lugar más sustentable para la diversidad medioambiental, amenazada por el colapso y la extinción. Esta disciplina con sus conocimientos, métodos y usos, se propone entonces como un medio comprensivo de ayudar a la construcción de la armonía entre el hombre y su medio, haciendo un uso virtuoso y proactivo de los potenciales que emergen de la relación entre mapas digitales y sociedad.

\section{BIBLIOGRAFÍA}

BASUlto GALlEgOS, O. (2012): «Construcción de valor territorial en el imaginario urbano» En: RIPS, Vol. 12, núm. 2, 115-126

BeltRÁN, G. (2014): Geomárketing: Geolocalización, redes sociales y turismo. Publicado por@Gersonbeltran, España.

BENEDETTO, A. (2010): El lugar y la identidad: aportes para El desarrollo local en áreas rurales de la provincia de Mendoza. Estrategias con identidad territorial. Tesis Doctoral, Universidad de Cuyo, Argentina.

BUZAI, G. D. (2001): «Paradigma Geotecnológico, Geografía Global y CiberGeografía, la gran explosión de un universo digital en expansión». En: GeoFocus (Artículos), $\mathrm{n}^{\circ} 1,24-48$.

CASTELLS, M. (2001): La galaxia internet. Barcelona, Plaza y Janés.

CERDA Seguel, D. (2005): «El mundo según google. Google Earth y la creación del dispositivo geosemántico global». AAInteligencia.cl, Chile. 
http://www.escaner.cl/escaner86/ensayo.html

https://sites.google.com/site/geosemanticagearth/

Cerda Seguel, D. (2008): «Tierra, sentido y territorio: la ecuación geosemántica». Escáner Cultural, Chile.

http://www.aainteligencia.cl/?p=133

http://revista.escaner.cl/node/693

Cerda Seguel, D. (2013): «Más allá del sentido de lugar. Geosemántica social, ciencia del territorio». Escáner Cultural, Chile.

http://revista.escaner.cl/node/7137

CURRAN, K.; CRUMLISH, J.; FISHER, G. (2012): «OpenStreetMap» En: International Journal of Interactive Communication Systems and Technologies, 2(1), 69-78.

Deleuze, G. (1969): Lógica del sentido. Paidós, Barcelona, España, 2005 (1969).

Deleuze, G.; GuatTARI, F. (1993): ¿Qué es la filosofia? Anagrama, Barcelona.

Fustel De Coulanges, N. (1982): La ciudad antigua. Editorial EDAF. Madrid.

GoodCHILD, M. F. (2007): «Citizens as sensors: web 2.0 and the volunteering of geographic information». En: GeoFocus (Editorial), no ${ }^{\circ}$, p. 8-10, ISSN: 1578-5157. http://nbn-resolving.de/urn:nbn:de:0114-fqs1202144

GrAHAM, M. (2009) «Neogeography and the palimpsest of place: web 2.0 and the construction of a virtual Earth». Tijdschrift voor Economische en Sociale Geografie, Vol. 101, No. 4, 422-436.

Harvey, F. (2013): «A New Age of Discovery: The Post-GIS Era». Ponencia en: GI_Forum 2013. Creating the GISociety (JeKel, T., CAR, A., Strobl, J. \& GRIESEBNER, G., Eds.). Herbert Wichmann Verlag, VDE VERLAG GMBH, Berlin/Offenbach, 272-281

Kosiva, S.; BAUER, A. M. (2013): «Mapeando el paisaje político: hacia un análisis SIG de las diferencias medioambientales y sociales» En: Cuadernos del Qhapaq Ñan Año 1, $\mathrm{N}^{\circ} 2,120-160$.

Pfeilstetter, R. (2011). «El territorio como sistema autopoiético». Periferia, Revista de recerca i formació en antropología, Universidad Autónoma de Barcelona, $\mathrm{n}^{\circ} 14,1-17$.

http://www.raco.cat/index.php/Periferia/article/download/244163/327010 (consultado el 10/02/2015).

PorTmanN, E. (2012): «The Social Semantic Web» En: The FORA Framework, Fuzzy Management Methods. Springer Science \& Business Media, Dec 30, 13-36. Springer-Verlag Berlin Heidelberg. DOI 10.1007/978-3-642-33233-3_2

RAFFESTIN, C. (1980): Por una geografía del poder. El Colegio de Michoacán. Edición en e-book, 2011.

SchmitT, C. (2013): Teoría del partisano. Trotta Editorial

SCHNEIDER et al. Review of Argumentation for the Social Semantic Web. The Open University, UKA, 2013. 1570-0844/0-1900.

SCHNEIDER, S.; PeYré TARTARUga, I. G. (2006): «Territorio y enfoque territorial: de las referencias cognitivas a los aportes aplicados al análisis de los procesos sociales rurales» En: Desarrollo Rural. Organizaciones, Instituciones y Territorio. Ed. Ciccus, Buenos Aires.

SchUTZ, A. (1989): La Construcción significativa del mundo. Paidós, Barcelona. 
Subires-MANCERA, Ma P. (2012): «Cartografía participativa y web 2.0: estudio de interrelaciones y análisis de experiencias». En: Revista de Comunicación Vivat Academia, Año XIV, No Especial. Febrero 2012, 201-216.

TURNER, A. (2006): Introduction to Neogeography. O'Reilly Short Cuts series. O'Reilly Media

VERD, J. M.; PORCEL, S. (2012): «An Application of Qualitative Geographic Information Systems (GIS) in the Field of Urban Sociology Using ATLAS.ti: Uses and Reflections» [48 paragraphs]. En: Forum Qualitative Sozialforschung / Forum: Qualitative Social Research, 13(2), Art. 14.

WeBER, M. (1992): «Sociología de la Dominación». En: Economía y Sociedad. FCE. México.

WINTHER, R. H. (2014): «Mapping Kinds in GIS and Cartography. Natural Kinds and Classification in Scientific Practice». En: Natural Kinds and Classification in Scientific Practice, Chapter: Mapping Kinds in GIS and Cartography. Editors: Catherine Kendig. Publisher: Pickering and Chatto, London, R.U.

ZAPIAIN AIZPURU, $\mathrm{M}^{\mathrm{a}}$ T. (2011): «Reflexiones identitarias en el territorio contemporáneo. La construcción colectiva de lugar. Caso de estudio de la Vega de Granada». En: Cuadernos Geográficos, 48 (2011-1), 79-108.

\section{Artículos periodísticos y sitios web:}

$\checkmark$ «Yahoo Inc reportedly in talks to buy location-based app maker Foursquare for US\$900 million».

http://business.financialpost.com/business-insider/yahoo-inc-reportedly-intalks-to-buy-location-based-app-maker-foursquare-for-us 900 million? $1 \mathrm{sa}=47 \mathrm{~d} 9-\mathrm{a} 87 \mathrm{~b}$

$\checkmark$ http://www.openstreetmap.org

$\checkmark$ https://www.waze.com/es-419

$\checkmark$ http://www.galaxyzoo.org

\section{Artículos de Wikipedia en español e inglés:}

$\checkmark$ http://es.wikipedia.org/wiki/Prosumidor

$\checkmark$ http://en.wikipedia.org/wiki/mashup

$\checkmark$ http://en.wikipedia.org/wiki/Locative media

$\checkmark$ http://en.wikipedia.org/wiki/Neogeography

$\checkmark$ http://es.wikipedia.org/wiki/Noosfera

$\checkmark$ http://es.wikipedia.org/wiki/territorio

$\checkmark$ http://en.wikipedia.org/wiki/Georeference

$\checkmark$ http://en.wikipedia.org/wiki/social_media 